\title{
POLÍTICAS PÚBLICAS INTERSETORIAIS DE FORTALECIMENTO DA AGRICULTURA FAMILIAR: SEGURANÇA ALIMENTAR E NUTRICIONAL NA REGIÃO DO CARIRI, NO MUNICÍPIO DE JUAZEIRO DO NORTE- CEARÁ
}

\author{
Barbara Leandro Monteiro ${ }^{1}$ \\ Katia Cilene Tabai ${ }^{2}$
}

\begin{abstract}
Resumo: A dimensão e a intersetorialidade das Políticas Públicas em várias instâncias da sociedade civil, que de forma participativa integram os repasses a estados e municípios para compra de gêneros alimentícios provenientes da Agricultura Familiar, onde são fomentadas ações de Segurança Alimentar e Nutricional - SAN que com a pandemia da COVID-19, os desafios tornaram-se ainda maiores. O presente trabalho foi realizado no município de Juazeiro do Norte, no Ceará, sobre as políticas públicas de SAN. O estudo foi conduzido através de investigações de pesquisas de natureza quali-quantitativa descritiva com uso de dados das plataformas governamentais e a aplicação de questionário, respeitando os aspectos éticos. Diante da expansão da COVID-19 é pertinente fazer inferência ao aumento da insegurança alimentar dos mais vulneráveis, como os escolares de famílias pobres, pessoas em situação de vulnerabilidade social. Espera-se que este estudo venha a contribuir para a reformulação e a reestruturação de ações governamentais e políticas públicas voltadas para SAN.

Palavras-chave: Políticas Públicas; Segurança Alimentar e Nutricional; Programa Nacional de Alimentação Escolar.

\section{INTERSECTORAL PUBLIC POLICIES FOR STRENGTHENING FAMILY FARMING: FOOD AND NUTRITIONAL SECURITY IN THE REGION OF CARIRI, MUNICIPALITY OF JUAZEIRO DO NORTE - CEARÁ}

\begin{abstract}
The dimension and intersectoriality of Public Policies encompass various instances of civil society, which in a participatory way integrate the transfers to states and municipalities for the purchase of foodstuffs from Family Farming, where actions of Food and Nutritional Security are promoted which with the COVID-19, the challenges have become even greater. The present study was carried out in the municipality of Juazeiro do Norte, in Ceará, regarding public policies on Food and Nutritional Security. The study was conducted through investigations of descriptive qualitative and quantitative research using data from government platforms and the application of questionnaire, according to the ethical principles. In view of the expansion of COVID-19, it is pertinent to make inference to the increase of food insecurity of the most vulnerable, such as students from poor families, people in a situation of social vulnerability. It is expected that this study will contribute to the reformulation and restructuring of government actions and public policies aimed at Food and Nutritional Security.
\end{abstract}

Keywords: Public policy; Food and Nutritional Security; National School Feeding Program.

\section{Introdução}

A soberania alimentar e nutricional são temas que vêm tendo grande ênfase no Brasil e no mundo. Embora havendo um grande avanço, ainda é considerada de grande preocupação, pois, após um período de declínio constante, em 2015 onde houve uma redução na situação da fome no

\footnotetext{
${ }^{1}$ Doutoranda em Alimentos e Nutrição. Universidade Estadual de Campinas - UNICAMP. Faculdade de Engenharia de Alimentos - FEA. Mestre em Agricultura Orgânica pelo Programa de Pós-Graduação em Agricultura Orgânica PPGPAO. Universidade Federal Rural de Rio de Janeiro - UFRRJ. Engenheira Agrônoma. Grupo de Pesquisa do CNPq: Segurança Alimentar e Nutricional (SAN). Email: barbyleandro@gmail.com

${ }^{2}$ Professora Titular. Universidade Federal Rural do Rio de Janeiro - UFRRJ. Orientadora do trabalho. Líder do Grupo de Pesquisa do CNPq: Segurança Alimentar e Nutricional (SAN). Email: ktabai@ufrrj.br
} 
mundo, permanecendo a níveis estáveis de aproximadamente $11 \%$ por alguns poucos anos. Todavia, houve uma regressão e um aumento neste quadro, onde verificou-se que mais de 820 milhões de pessoas lamentavelmente passavam fome, o que se evidencia como sendo um desafio para o alcance da meta do Fome Zero até 2030 (FAO, 2018).

No Brasil, as Políticas de Segurança Alimentar e Nutricional (SAN) se consolidam, a partir de 2006, pelo Sistema Nacional de Segurança Alimentar e Nutricional (SISAN), que foi criado tendo como base a Lei Orgânica de Segurança Alimentar e Nutricional (LOSAN), na qual propõe assegurar o direito humano à alimentação adequada. Definindo que o estado tem o principal dever de respeitar, proteger, promover, prover, informar, monitorar, fiscalizar e avaliar a realização do direito humano à alimentação de maneira adequada, bem como garantir os mecanismos para sua exigibilidade e estabelecer diretrizes e objetivos da Política Nacional de Segurança Alimentar e Nutricional (PNSAN) (BRASIL, 2006).

A agricultura familiar tem papel importante na produção de alimentos e para o estabelecimento e consolidação da Segurança Alimentar. Neste sentido, os programas Programa Nacional de Alimentação Escolar (PNAE) e o Programa de Aquisição de Alimentos (PAA) se destacam como sendo elos fundamentais que promovem e incentivam a alimentação saudável e adequada através do estimulo da produção e consumo de alimentos oriundos da agricultura familiar, (MONTEIRO et al., 2019; TABAI, 2017).

Meirelles (2004), descreve soberania alimentar como sendo um direito universal de ter acesso a um alimento saudável e de boa qualidade dos povos, sobrepondo-se a todos os fatores sejam eles econômicos, políticos ou culturais que não permitam sua efetivação. Todas as pessoas devem ter direito e acesso a uma alimentação segura, culturalmente apropriada e em quantidade e qualidade suficientes para garantir o seu desenvolvimento integral.

Sabe-se que a governança alimentar e nutricional engloba o fortalecimento de canais de negociação intergovernamentais e a adoção de novos mecanismos de articulação entre instituições, mercados e múltiplos grupos de interesse locais e globais. Acredita-se que novos arranjos institucionais sejam cruciais para lidar, por exemplo, com a emergência de alimentos geneticamente transformados, fortificados e processados tecnologicamente de diferentes maneiras e que sabemos que impactam tanto a produção agrícola e industrial como o perfil das redes de comercialização e padrões de consumo (MAGALHÃES, 2014; TABAI, 2017).

A Lei Orgânica de Segurança Alimentar e Nutricional - LOSAN (BRASIL, 2006) estabelece que Segurança Alimentar e Nutricional consiste na realização do direito de todos ao acesso regular e de maneira permanente a alimentos de qualidade, em quantidade suficiente, sem que haja o comprometimento ao acesso a outras necessidades essenciais, baseando-se em práticas 
alimentares saudáveis que respeitem aspectos que condizem com a diversidade cultural, sendo ambiental, cultural, econômica e socialmente sustentáveis.

Em 2010, a alimentação passou a fazer parte dos direitos sociais previstos no artigo $6^{\circ}$ da Constituição Federal. Entretanto, o DHAA, se configura como algo que permanece distante da realidade em vários locais do mundo e com a pandemia da COVID-19, os desafios tornaram-se ainda maiores até porque o Índice de Desenvolvimento Humano - IDH do Brasil caiu 05 posições em relação ao último, foi de 0,762 em 2018 para 0,765 para 2019 , encontra-se em $84^{\circ}$ na posição mundial, entre 184 países, segundo o último relatório de Desenvolvimento Humano (IBGE, 2020).

Neste sentido, diante dos paradigmas enfrentados pelos agentes envolvidos no desenvolvimento e consolidação de tais políticas, e pela crescente demanda de alimentos é imprescindível o seu entendimento como um setor produtivo que deve ser motivado, dada sua importância, para que se possa esboçar, atender, manter e/ou até mesmo ampliar estímulos no intuito de promover a SAN como um todo (MONTEIRO et al., 2019).

Contudo, muitos são os fatores que afetam a condição de segurança alimentar e nutricional, dentre eles estão, a produção agrícola, o escoamento, o comércio, a qualidade dos alimentos, a qualidade da água, os serviços de saneamento, a cultura alimentar local, a governabilidade, a estabilidade política, etc.

Este trabalho versa sobre o estudo de caso realizado no município cearense de Juazeiro do Norte, localizado na porção sul do estado, acerca das políticas públicas intersetoriais que contemplam o munícipio.

\section{Universo da pesquisa}

O município de Juazeiro do Norte, localiza-se na microrregião do Cariri, ao sul do estado do Ceará, a 396 km de distância de Fortaleza (Figura 1). Tem como cidades fronteiriças, Crato, Barbalha Caririaçu e Missão Velha. Suas coordenadas geográficas são 7¹2'47’S e 39¹8'55”W. Foi emancipado em 22 de julho de 1911, possui uma área de 258,788 km², 276.264 habitantes e densidade demográfica de 1.004,45 hab./ km², Índice de Desenvolvimento Humano de 0,694 e PIB (Produto Interno Bruto) de 17.725,62 mil reais em 2018 (IBGE, 2021). 
Figura 1. Localização espacial do município em estudo. Juazeiro do Norte-CE, 2020.

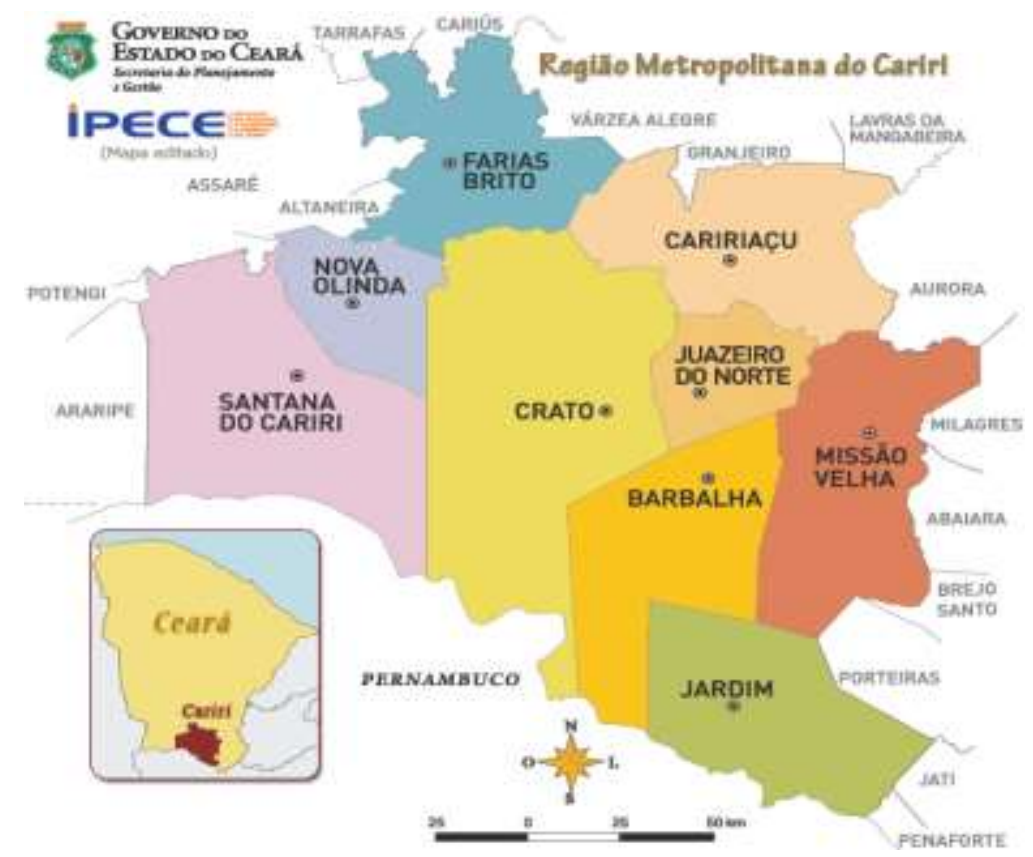

Fonte: Instituto de Pesquisa e Estratégia Econômica do Ceará (IPECE, 2010).

O município de Juazeiro do Norte está dentre as cidades que mais crescem no interior do Nordeste, ultrapassando os limites estaduais, sendo caracterizada como uma cidade média em crescente desenvolvimento. A princípio o impulso de expansão se dava pelo forte movimento das romarias, em prol do Padre Cícero, atualmente se tornou um grande polo para investimentos: indústria, principalmente calçadista, comércio de abrangência regional, serviços de educação, saúde entre outros.

Neste sentido, consequentemente o número populacional aumentou, consequentemente. O município contempla o alvorecer do desenvolvimento econômico e os limites da utilização dos recursos naturais onde não contemplou a sustentabilidade ambiental almejada pela proposta da sociedade nos últimos anos. São expressivos os impactos nas formas de relevo pelas construções e fluxos, principalmente as erosões aceleradas em terrenos com urbanização ainda não consolidada.

Dos 258,788 Km² de Juazeiro do Norte, 10.539 hectares são pertencentes a Zona Rural do Município. Porém, ressaltamos que estes dados são uma aproximação da realidade do Município que evidencia uma forte expansão da zona Urbana. Há comunidades que estão localizadas formalmente na Zona Urbana, mas que seus residentes consideram como rurais pela vivência de seu cotidiano, seus costumes, atividades produtivas ligadas à agricultura, etc. (IBGE, 2018). 
Analisando o índice de Gini (utilizado para medir as desigualdades na distribuição da terra) no Brasil, observou-se que na estrutura ainda se evidencia um alto grau de concentração na estrutura fundiária brasileira permanecendo intangível de maneira expressiva por entre 1985 e 2006, e notando-se um aumento de acordo com último censo. Segundo o Censo Agropecuário 2017, o índice de Gini brasileiro registrou 0,867 pontos, se mostrando com um leve aumento quando comparado aos dados observados em pesquisas que antecederam este censo onde, 0,854 (2006), 0,856 (1995-1996) e 0,857 (1985). É importante destacar que quanto mais perto essa medida está do número 1, maior é a porcentagem de concentração na estrutura fundiária. Onde o estado do Ceará apresentou (2,0\%). Essa desigualdade é mais elevada no Estado do Maranhão aprensentando 0,888 (IBGE; 2020).

\section{Método de obtenção dos dados}

O estudo foi conduzido através de investigações de pesquisas de natureza quali-quantitativa descritiva, sendo empregada à avaliação de programas governamentais, em especial no que tange a questão da intersetorialidade, com enfoque nos programas PAA e PNAE. Fez-se uso também, de dados disponíveis pelo Instituto Brasileiro de Geografia e Estatística (IBGE), pelo Fundo Nacional de Desenvolvimento da Educação (FNDE), SAGI (plataforma do PAA data), da Secretaria Especial de Agricultura Familiar e do Desenvolvimento Agrário (SEAD) e serviu como referencial metodológico principalmente os trabalhos de Neves (2018), Santos (2018), Neves e Tabai (2017), Bezerra e Tabai (2018), Monteiro (2020).

Fez-se uso de várias técnicas como entrevistas, aplicação de questionários, preenchimento de formulários, e o emprego de procedimentos de amostragem. A pesquisa de campo se caracteriza quando o pesquisador apresenta objetivo para conseguir informações e conhecimentos acerca de um problema, na qual se busca uma resposta (LAKATOS e MARCONI, 2001).

Essa pesquisa é um recorte do projeto aprovado pela Comissão de Ética e Pesquisa (COMEP) da UFRRJ, de acordo com os princípios éticos da Resolução 466/12 do Conselho Nacional de Saúde, ao qual regulamenta os procedimentos de pesquisa envolvendo humanos sob protocolo $\mathrm{n}^{\circ} 797 / 2016$, e propõe investigações de pesquisas com a principal finalidade de delineamento ou análise de características de fatos, intitulado: "Segurança alimentar e intersetorialidade no Brasil".

Os dados coletados foram organizados e agrupados por ano e município na plataforma do FNDE constavam apenas os valores totais das aquisições para a alimentação escolar e os valores das aquisições oriundos da Agricultura Familiar por ano. Para a organização e análises dos dados 
e estatísticas foi utilizado o Microsoft Excel@, e a criação das tabelas com os valores absolutos e percentuais dos itens analisados no Microsoft Word®.

\section{Resultados e discussão}

\section{Programa Nacional de Alimentação Escolar - PNAE em Juazeiro do Norte}

A princípio, na aplicação dos questionários, buscou-se entender como funciona a dinâmica produtiva local e a forma como estes produtores se organizam. Para isso, as reuniões realizadas por eles nortearam na identificação destes produtores, a forma como estes produzem e como eles interagem entre si.

Em relação à produção na região metropolitana do Cariri, em especial no município de Juazeiro do Norte, sabe-se que é formada por produtores familiares. Estes produtores se associam e se reúnem duas vezes no mês, com intuito de garantir a sobrevivência e perpetuação dos saberes. Nestas reuniões são abordados temas referentes à agroecologia, selo de Agricultura Familiar, circuito de feiras da região, exposições dos seus produtos, projetos, fortalecimento das casas de sementes crioulas, economia solidária, convênios e parcerias firmados com entidades locais, entre outros.

Os agricultores familiares locais enfrentam dificuldades estruturais que têm relação com a insuficiência de apoio técnico responsável pelo serviço de Ater no município, o que sugere a necessidade de fortalecimento de parcerias entre estes agricultores e as entidades de fomento à assistência técnica. No entanto, estes mesmos agentes não conseguem suprir o volume demandado pelos agricultores, pois ocorre que a prestação deste serviço se encontra sob dificuldades estruturais severas como o acesso às propriedades, operacionalização dos serviços, logística, insuficiência de recursos limitações em relação ao corpo técnico, limitações relacionadas ao saneamento e a falta de água.

Os alimentos produzidos são oriundos do sistema de produção dito como de base agroecológica $^{3}$, tendo ênfase para um cultivo consciente, sem uso de insumos danosos à saúde humana e ao meio ambiente (CAPORAL e COSTABEBER, 2001).

\footnotetext{
${ }^{3}$ Entende-se por de base agroecológica, pois os métodos de produção obedecem algumas características pertinentes aos métodos adotados nos sistemas de produção orgânicos, no qual há uma sensibilização por parte dos produtores na hora de produzir, onde não fazem uso de agrotóxicos e adotam práticas agroecológicas para manejo do solo e diversificação das culturas, e comercialização. No entanto, devido ao custo necessário para obtenção e manutenção do selo orgânico ou até mesmo a desinformação destes produtores, ainda há uma resistência por parte de alguns produtores em adquiri-lo e as características locais ainda não favorecem ao produtor se certificarem, tornando-se um processo oneroso(CAPORAL e COSTABEBER, 2001).
} 
O município conta com a COOPAEFARC congrega 167 cooperados e fica localizada na comunidade Açude dos Carneiros, distrito de Palmeirinhas, no município de Juazeiro do NorteCE, cultivando frutas e olerícolas como: cebola, abacate, tomate, pimentão, manga, banana, mamão, goiaba, abacaxi, acerola, pimenta e folhosas, para venda in natura e produtos beneficiados. A pecuária é constituída pela criação de gado leiteiro e de corte e também, produção de queijo, e produtos lácteos. Boa parte do que produzem é destinado PNAE, onde possibilita destinar as escolas a aquisição de no mínimo 30\% dos repasses devem ser destinados à compra de gêneros alimentícios provenientes da agricultura familiar. A cooperativa também destina sua produção para o PAA e para feiras livres que inclui o circuito de feiras da microrregião do cariri cearense (SDA, 2020).

O uso de cultivo protegido também tem possibilitado um bom desempenho para os agricultores familiares do município, que contam com apoio de projetos que tem possibilitado melhoria da qualidade da produtividade, se tornando meio mais eficiente o sistema de plantio proporcionando o uso racional de água e facilitando o controle biológico de pragas e até mesmo doenças (EMATERCE, 2020).

O setor agropecuário brasileiro que possui papel fundamental na promoção da segurança Alimentar e Nutricional, é responsável construção primária de importantes cadeias produtivas, no Brasil a política agrícola auxilia o setor através de políticas, programas e instrumentos públicos que conferem suporte para produção mais precisamente para Agricultura Familiar - O PRONAF. Para enfrentamento dos efeitos negativos oriundos da expansão da crise que adveio da pandemia da COVID-19 juntamente com os efeitos que repercutiram na produção e comercialização dos alimentos, dificultando o escoamento, impondo barreiras ao acesso e causando desequilíbrio, para reduzir os impactos originados da crise, foram implementadas medidas que possibilitaram auxilio econômico a agricultores afetados pela pandemia da COVID-19, além de outras medidas que provinham recursos para as pessoas em situação de vulnerabilidade (VALADARES et al. 2020; SDA, 2020).

Segundo Neves e Tabai (2020), a intersetorialidade é um ofício laborioso que requer a convergência de mecanismos distintos e a sua integração é arduamente complexa no que concerne à promoção da SAN.

Segundo dados da prefeitura do município de Juazeiro - CE, durante o ano de 2020 diante da grande expansão do COVID-19 e a vulnerabilidade que lamentavelmente fragilizou muitas famílias, a cooperativa desempenhou um papel crucial para o município mediante ação conjunta para a doação de produtos agrícolas, o Serviço Social do Comércio-SESC que notadamente é 
representado pelo programa "Mesa Brasil" e o "Banco de Alimentos" da Secretaria de Ação Social (Figura 2).

Figura 2. Triagem dos gêneros alimentícios no Banco de Alimentos em Juazeiro do Norte - CE
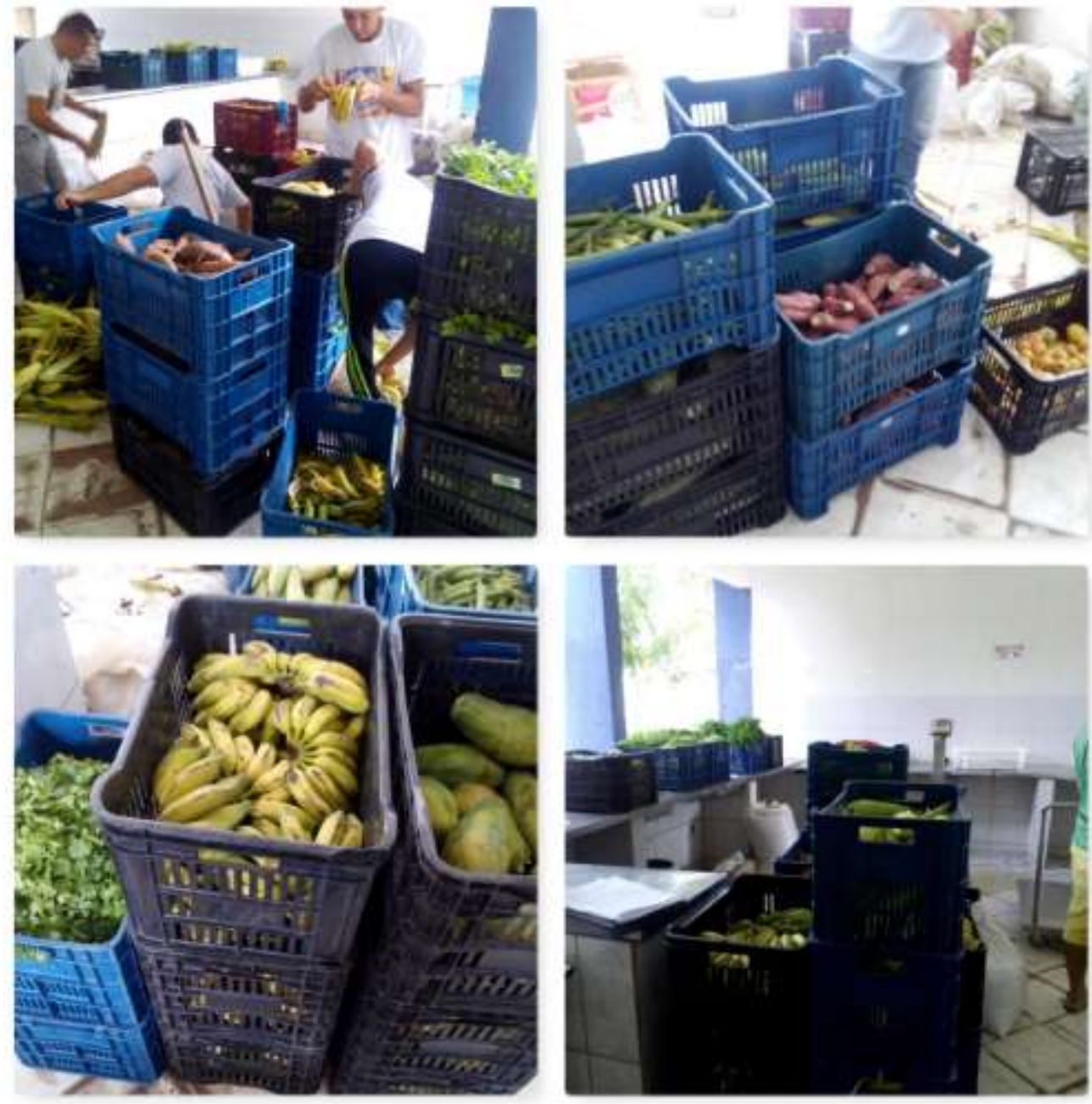

Fonte: Fotos capturadas pelas autoras.

Esses programas que se evidenciam através do objetivo de recolher doações de produtos alimentícios da microrregião, como também daqueles provenientes da agricultura familiar e dos supermercados, destinando-os às famílias em situação de vulnerabilidade social que habitam as periferias da sede municipal.

Dos dados disponibilizados pelo Fundo Nacional de Desenvolvimento da Educação referentes aos anos de 2011 a 2018, é possível analisar que houve uma boa adesão do município ao que é estabelecido pela lei $\mathrm{n}^{\circ}$ 11.947/2009 que estabelece que no mínimo 30\% dos repasses devem ser destinados a compras de gêneros alimentícios provenientes da Agricultura Familiar. Logo, o município conseguiu atender de modo eficiente o estabelecido por lei ao longo dos anos 
analisados, o que demonstra um maior engajamento destes agricultores ao programa nesse município. Que somente nos anos de 2011 (0\%) e 2013 (7,06\%) não conseguiram atender de maneira satisfatória estabelecido pela lei n ${ }^{\circ} 11.947 / 2009$, conforme consta na tabela 1 . Os produtos adquiridos com o recurso do PNAE no período avaliado foram fornecidos por cooperativas de agricultura familiar pertencente ao município recebedor.

Tabela 1: Repasse e compra da Agricultura Familiar equivalente aos anos de 2011 a 2016, Juazeiro do Norte - CE

\begin{tabular}{cccc}
\hline Ano & $\begin{array}{c}\text { Valor total } \\
\text { das compras (r\$) }\end{array}$ & Valor AF(r\$) & $\begin{array}{c}\text { Percentual } \\
\text { de compras da } \\
\mathbf{A F}(\boldsymbol{\%})\end{array}$ \\
\hline 2011 & $4.081 .080,00$ & 0 & $0 \%$ \\
2012 & $3.422 .773,67$ & $2.935 .800,00$ & $85,77 \%$ \\
2013 & $3.194 .720,00$ & $225.480,00$ & $7,06 \%$ \\
2014 & $3.195 .090,00$ & $1.503 .039,16$ & $47,04 \%$ \\
2015 & $3.568 .738,00$ & $1.793 .530,59$ & $50,26 \%$ \\
2016 & $3.368 .057,43$ & $1.075 .345,68$ & $31,93 \%$ \\
2017 & $3.544 .735,54$ & $1.208 .768,47$ & $34,10 \%$ \\
2018 & $1.615 .976,99$ & $854.715,06$ & $52,89 \%$ \\
\hline
\end{tabular}

Fonte: FNDE, 2018

O gráfico 1 a seguir retrata a linha do tempo durante o período que vai desde 2011 a 2018 que se tenha uma melhor visualização acerca da evolução do programa no município. Nele podese observar um decréscimo na curva relacionada a porcentagem $(\%)$ de compras de gêneros oriundos da agricultura familiar.

Gráfico 1: PNAE Juazeiro do Norte - CE

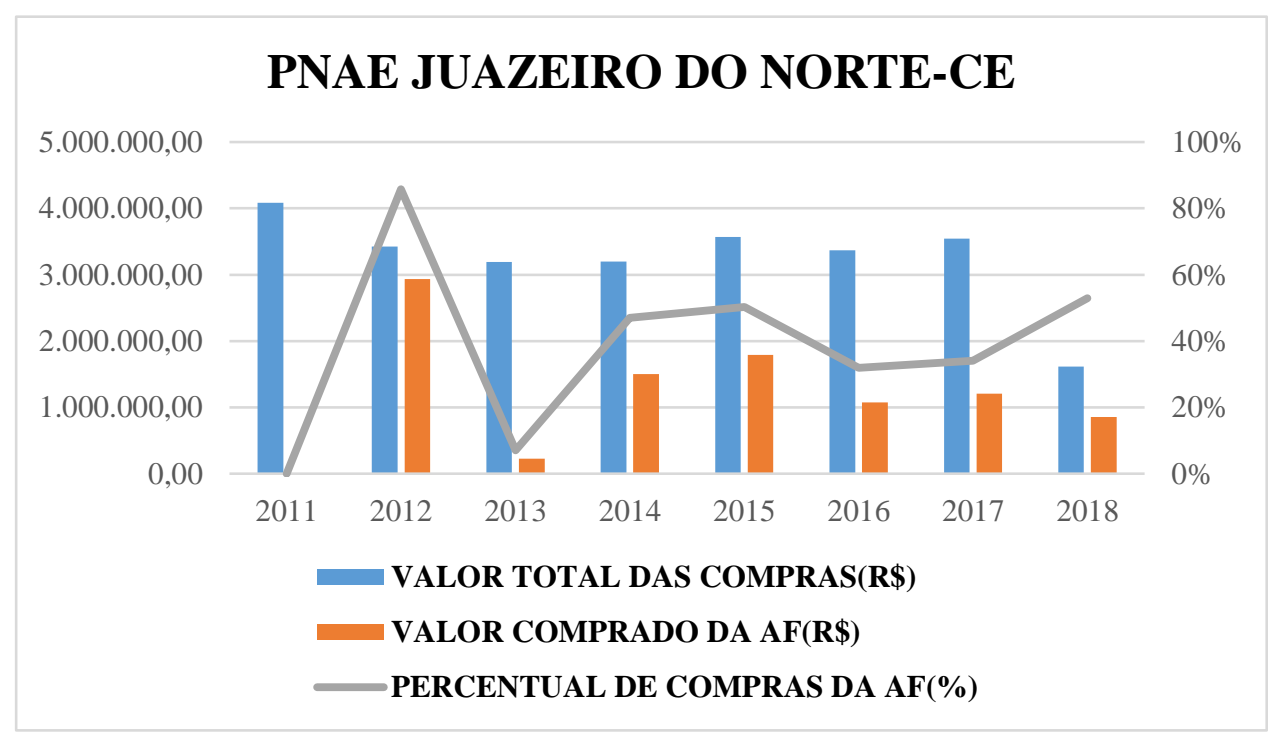

Fonte: Elaborado pelas autoras, 2020. 
Em 2020 o FNDE por meio de Nota Técnica divulgou mudanças nos aspectos de segurança alimentar e nutricional na legislação do PNAE, onde direciona aos executores do programa a orientação em relação aos cardápios para as creches, retirando açúcar e alimentos ultraprocessados (FNDE, 2020).

Tendo em vista que muitos estudos mencionam o impacto do consumo na saúde e fazendo inferências da relação entre o consumo destes alimentos à obesidade e outras patologias. Onde o principal enfoque do PNAE é trabalhar na educação alimentar e no estabelecimento de hábitos alimentares saudáveis, promovendo melhor qualidade de vida e evitando que se tenha um aumento ainda maior de doenças futuramente.

Durante este período de pandemia, ainda em 2020, foi promulgada a Lei $\mathrm{n}^{\circ} 13.987$ que permite a distribuição dos gêneros alimentícios que foram adquiridos através de recursos oriundos do PNAE sendo destinados de maneira direta para os estudantes beneficiários. Em consoante a este decreto, estabeleceu-se resoluções que definiram as regras acerca desta distribuição, como também, orientações que norteiam as compras de produtos oriundos da agricultura familiar no decorrer deste momento tão delicado.

O setor agropecuário brasileiro que possui papel fundamental na promoção da Segurança Alimentar e Nutricional - SAN, é responsável construção primária de importantes cadeias produtivas, no Brasil a política agrícola auxilia o setor através de políticas, programas e instrumentos públicos que conferem suporte para produção mais precisamente para agricultura familiar - O PRONAF. Para enfrentamento dos efeitos negativos oriundos da expansão da crise que adveio da pandemia da COVID-19 juntamente com os efeitos que repercutiram na produção e comercialização dos alimentos, dificultando o escoamento, impondo barreiras ao acesso e causando desequilíbrio, para reduzir os impactos originados da crise, foram implementadas medidas que possibilitaram auxilio econômico a agricultores afetados pela pandemia da COVID19, além de outras medidas que provinham recursos para as pessoas em situação de vulnerabilidade (MONTEIRO, 2020).

Segundo Neves e Tabai (2020), a intersetorialidade é um ofício laborioso que requer a convergência de mecanismos distintos e a sua integração é arduamente complexa no que concerne à promoção da SAN.

Em se tratando de políticas públicas, Custódio e Silva (2015) sustentam a relevância de se conectar tais práticas com as demais áreas da sociedade, uma vez que a visão setorializada e a fragmentação de ambos é custosa e ineficiente, visto que gera condutas e respostas distantes das orientações e propósitos esperados. Nesse quesito, a intersetorialidade entra como instrumento de gestão, pois necessita-se considerar a relevância da interação de diversas entidades e órgãos no 
engajamento para o alcance de direitos e da atuação social como exigência de autenticidade das políticas públicas.

Deste modo, no ambiente público, um atributo fundamental destacado no Art. 218 da Constituição Federal Brasileira de 1988, menciona que o estado deve provê o direcionamento através de meios que mitiguem questões de difícil resolução da sociedade brasileira e promova da mesma maneira o desenvolvimento tanto para o contexto regional quanto para o nacional, a saber:

Art. 218. O Estado promoverá e incentivará o desenvolvimento científico, a pesquisa, a capacitação científica e tecnológica e a inovação.

$\S 2^{\circ}$ A pesquisa tecnológica voltar-se-á preponderantemente para a solução dos problemas brasileiros e para o desenvolvimento do sistema produtivo nacional e regional (BRASIL, 1988).

O estado concomitantemente com instituições privadas mostra-se como intercessor no município para o acesso as Políticas Públicas, que possibilitam incentivo aos agricultores familiares, sejam eles convencionais ou orgânicos. Dentre as principais políticas é possível destacar: o Programa de Aquisição de Alimentos - PAA; o Programa Nacional de Alimentação Escolar - PNAE; o Garantia Safra; a Política Nacional de Assistência Técnica e Extensão Rural PNATER; o Programa Nacional de Fortalecimento da Agricultura Familiar - PRONAF e o Plano Nacional de Agroecologia e Produção Orgânica - PLANAPO que promovem estímulo e apoio a manutenção do agricultor no campo, financiando projetos, que promovam melhores condições para que se tenha geração de renda proveniente das atividades produtivas desenvolvidas no meio rural as quais esses agricultores familiares desenvolvem (ALCÂNTARA e PERTILE, 2014).

Segundo Valadares et al. (2020), como resultado da diminuição dos canais de comercialização e das dificuldades de logística e seus efeitos negativos para a sociedade de maneira geral, diminuindo a renda dos agricultores familiares e suprimindo o acesso à alimentação adequada para os indivíduos em situação de vulnerabilidade. Como também ocasionando perdas na propriedade por falta de escoamento. E como consequência o desabastecimento, aumento de preços e por fim o aumento do número de pessoas em situação de fome.

\section{(In) Segurança alimentar e nutricional e a pandemia da Covid-19}

A doença do Coronavírus (COVID-19) é uma doença altamente infecciosa que tem como agente causal um vírus recém-descoberto denominado SARS COV 2 ou comumente chamado de COVID 19 ou CORONAVÍRUS. A maioria das pessoas que adoece em decorrência da COVID19 apresentará sintomas leves a moderados. Ele é transmitido principalmente por meio de gotículas geradas quando uma pessoa infectada expele por meio de espirros, tosses, etc. Essas gotículas são 
muito pesadas para permanecerem no ar e são rapidamente depositadas em pisos ou superfícies, possibilitando a infecção pelo agente patogênico (IBGE, 2020). No mundo, até o dia 16 de fevereiro de 2021, foram confirmados 109.617.818casos de COVID-19, sendo 192.266 novos casos. O número de óbitos foi de 2.421.592. Já no Brasil, a situação da COVID-19 tem aumentado exponencialmente, o número de casos chega a 9.921.981, sendo um total de 8.847.264 de casos recuperados e 240.940 vítimas que lamentavelmente foram acometidas por este vírus e tiveram óbito. No estado do Ceará o número de infectados é de 397.442 estando recuperados 299.059 casos e o somatório de mortes é de 10.850. Já no município estudado o número de infectados foi de 17.634 casos notificados, 16.909 recuperados e 355 vítimas (SUS, 2021). Em alguns países, como no Brasil, algumas vacinas contra a COVID-19 receberam aprovação das agências de controle para uso emergencial. No entanto, tendo em vista o número reduzido de vacinas, no Brasil, ainda se fazem necessárias medidas de prevenção e combate a propagação do vírus, impedindo que ele se espalhe, ainda mais em áreas com maior vulnerabilidade, pois como relatam alguns autores, como Silva (2020), o risco de contágio nesses locais é ainda maior.

Para que se possa dimensionar o impacto da pandemia para a população, é preciso analisar duas dimensões que sofreram de maneira expressiva, a dimensão alimentar e a nutricional diretamente afetadas. Ambas tem por missão garantir alimentos saudáveis, que respeitem aspectos pertinentes à cultura alimentar da população e que tenham sido produzidos de forma sustentável tendo sido afetadas drasticamente pela pandemia COVID-19. Nesse sentido, cabe colocar quais eixos foram suprimidos podendo-se destacar a disponibilidade de alimentos que durante a pandemia sofreu prejuízos na oferta de alimentos in natura da agricultura familiar (AF), especialmente as frutas e os vegetais; paralisação do PNAE e aquisição de alimentos da AF em alguns locais; feiras e equipamentos de venda e comercialização de alimentos foram paralisados, inclusive restaurantes. Houve também redução ou suspensão de renda para os mais vulneráveistrabalhadores informais; reduzindo o consumo de alimentos in natura; possibilitando um aumento do ganho de peso e/ou transtornos alimentares (SAMBUICHI et al., 2020).

Segundo Silva (2020), lamentavelmente os custos elevados de mortes durante a pandemia do Coronavírus tem relação direta com a má nutrição e a pobreza, neste sentido ele afirma que:

A medida que aumenta o número de mortos vão se consolidando as estatísticas de que além dos idosos, são os obesos e os pobres os que mais morrem. E como nas sociedades afluentes, o sobrepeso já se tornou "normal" (e não é visto como um grave problema de saúde pública, especialmente quando associado a outras enfermidades não transmissíveis como diabetes, hipertensão e problemas cardíacos diversos), o efeito do coronavírus tem sido muito mais devastador do que se conseguiu prever inicialmente [...] não há uma solução definitiva a nível local e individual se não houver uma solução global também (SILVA, 2020, p.3). 
Conforme o combate à fome evoluiu, as vulnerabilidades e os descompassos nos sistemas alimentares globais se acentuaram na pandemia de Covid-19. Neste sentido, todas as atividades e processos que se relacionam com a produção, o escoamento e o alimentar-se de fato foram comprometidos. Não obstante, uma avaliação do nível total do impacto ainda seja muito prematura. Todavia, pode-se inferir um aumento inimaginável como sendo resultante da estagnação econômica de alguns países que se originou a partir da forte evolução e expansão da Covid-19 no mundo. Nesta perspectiva, a consecução do segundo Objetivo do Desenvolvimento Sustentável - ODS 2 (acabar com a fome) retrocede de maneira drástica, infelizmente (AMORIM et al., 2020; VALADARES et al.,2020)

Maluf (2020) faz considerações acerca dos debates voltados para a temática fome no Brasil, pois durante a expansão da pandemia da COVID-19, os diálogos pertinentes aos danos decorrentes das mesma tem se intensificado destacando a importância destes debates:

\begin{abstract}
A promoção de debates virtuais periódicos é acompanhada pela proposta de instituir painéis de especialistas para se debruçarem sobre temas de SSAN e DHA, valendo-se do conhecimento acumulado entre os integrantes da Rede e pesquisadores residentes no exterior que com ela colaboram. A propósito, é essencial preservar e estimular, de forma permanente, a perspectiva de ter em conta o âmbito internacional, tanto por serem internacionais muitos dos fenômenos (MALUF, 2020, p.4).
\end{abstract}

Juntamente ao retorno do Brasil para o Mapa da Fome, a Pandemia de COVID- 19 e o desprovimento de renda afetou milhões de brasileiros não somente nas cidades como também no campo onde a desconstrução de políticas que favoreciam a agricultura familiar e possibilitava o desenvolvimento foram suprimidas.

Em relação ao município estudado e à agricultura familiar, as consequências das medidas para combate e prevenção da COVID-19 ocasionou maior dificuldade para que estes agricultores pudessem comercializarem seus produtos, pois com a redução do funcionamento dos estabelecimentos, escolas, feiras, restaurantes etc., impossibilitou que se pudesse escoar a produção e impediu que se houvesse a logística de distribuição (Figura 3). Ainda assim, alguns optaram pela venda de cestas e atendimento de maneira digital. 
Figura 3. Gêneros alimentícios da Agricultura Familiar de Juazeiro do Norte - CE.

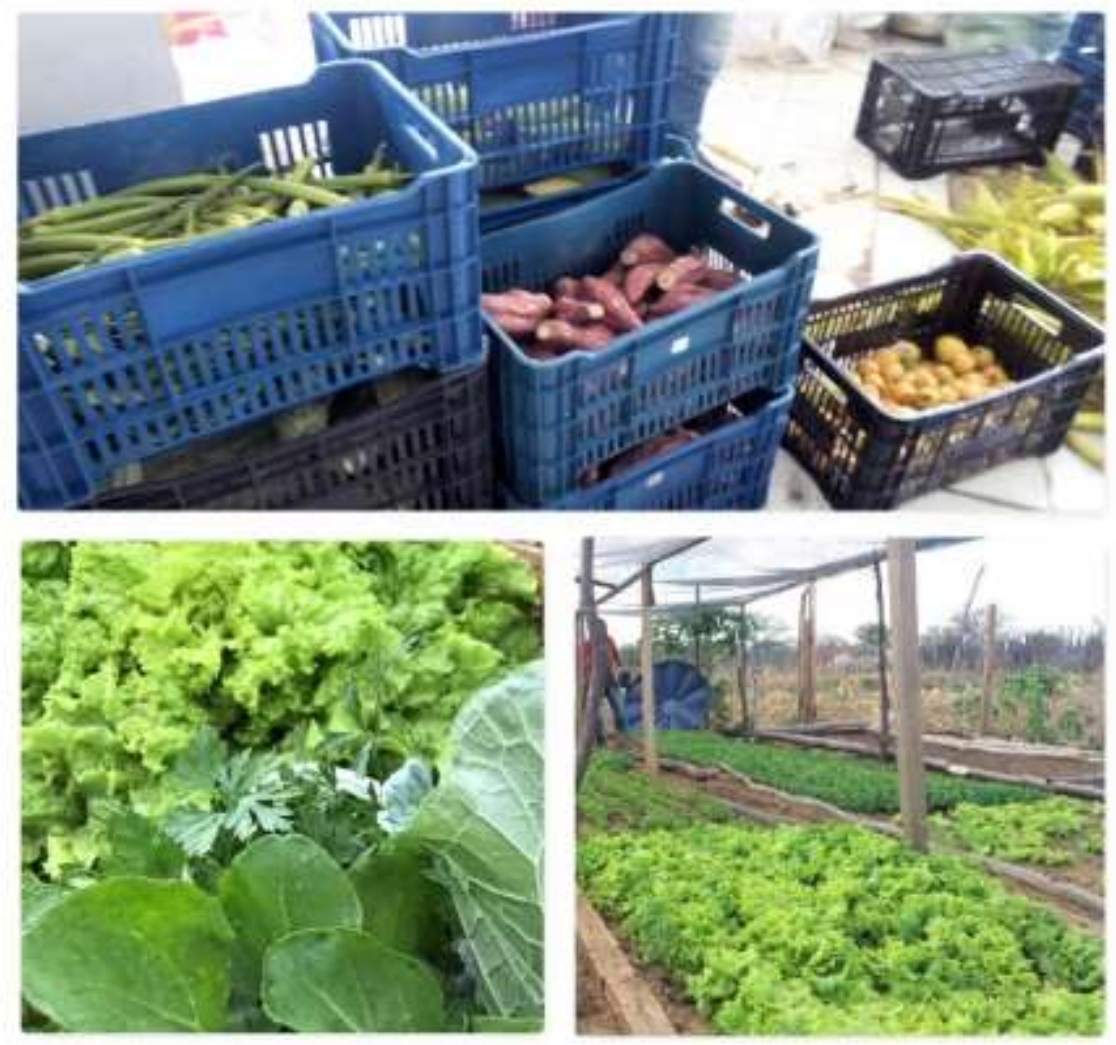

Fonte: Fotos capturadas pelas autoras.

Alguns autores como Alpino et al (2020) descreveram algumas ações que foram propostas para atenuar a crise, como o auxílio emergencial disponibilizado pelo governo federal e a liberação da distribuição da alimentação escolar, mas são evidentes os retrocessos na área de segurança alimentar e nutricional na gestão atual do Governo Federal, ainda mais com a pandemia da COVID-19. E ainda destaca como no Brasil, a pandemia amplifica as desigualdades sociais, raciais e de gênero já existentes, comprometendo ainda mais a garantia do Direito Humano à Alimentação Adequada (DHAA) e a concretização da segurança alimentar e nutricional, especialmente entre os mais vulneráveis. E outros autores como Amorim et al (2020) elucidaram a necessidade da construção de estratégias para que o PNAE possa garantir a alimentação dos escolares durante a suspensão das aulas devido a pandemia do COVID-19 como a distribuição de kits ou refeições para escolares; a ampliação do valor repassado pelo PNAE principalmente para os municípios com pessoas vivendo em maior vulnerabilidade, tomando como base o Índice de Desenvolvimento Humano (IDH) baixo e muito baixo e a manutenção e incentivo a aquisição de alimentos da agricultura familiar. 


\section{Considerações finais}

A compra institucional de alimentos impulsiona a criação de mercados locais e amplia as condições de acesso aos agricultores familiares. A adoção destes modelos de políticas públicas faz emergir várias formas de mitigação de problemas que necessitam ser resolvidos de maneira intersetorial.

Todavia, os dados apontam para uma melhoria nas condições de acesso a estas políticas onde se faz presente uma ampla participação da sociedade civil local, como também nas ações intersetoriais de modo contínuo. A partir dos resultados obtidos, pode-se perceber que no município estudado houve uma maior participação dos agricultores possibilitando o cumprimento da lei no $11.947 / 2009$.

O processo de fortalecimento da aquisição de alimentos diretamente da Agricultura Familiar pelos programas PAA e PNAE é complexo, pois sua efetiva realização requer uma série de condições que superam as condições do campo de atuação das esferas políticas adentrando no contexto social e produtivo entrelaçando-se em prerrogativas que condizem com melhorias na qualidade de vida de todos os envolvidos.

Sendo assim, cabe ao setor público que administra os programas, transparência e facilidade de acesso dos agricultores a estas políticas públicas como também o fornecimento de dados confere grande importância para o desenvolvimento de políticas intersetoriais promovendo a geração de renda, acesso a mercados e atendimento às necessidades de melhorias voltadas para atuação na promoção da Segurança Alimentar e Nutricional e do fortalecimento da Agricultura Familiar.

Ressalta-se a importância do acesso a alimentos de modo que atendam as deliberações estabelecidas pela LOSAN, pois a partir de tais medidas tem-se uma redução da situação da fome e desigualdade no município durante o período de 2011 a 2018.

Todavia, diante do momento pandêmico pelo qual estamos vivenciando e que refletiu em uma crise ainda maior do que a qual já estávamos vivenciando, é pertinente fazer inferência ao aumento da insegurança alimentar dos mais vulneráveis, como os escolares de famílias pobres, pessoas em situação de vulnerabilidade social.

Espera-se que este estudo venha a contribuir para a reformulação e a reestruturação de ações governamentais e políticas públicas voltadas para SAN, suprindo não somente as deficiências ainda existentes como também preenchendo as lacunas ainda constantes neste sistema visando o que é preconizado, a saber, sistemas alimentares saudáveis e sustentáveis. 


\section{Referências}

ALCANTARA, Andéia Silva de; PERTILE, Noeli, Agricultura familiar e os desafios na transição agroecológica: o caso do município de Rio Real, na Bahia. Análise \& Dados. Salvado, vol.24, n.2, p. 311-326, abril/junho, 2014.

AMORIM, Ana Laura Benevenuto de; RIBEIRO JR, José Raimundo Sousa; BANDONI, Daniel Henrique. Programa Nacional de Alimentação Escolar: estratégias para enfrentar a insegurança alimentar durante e após a COVID-19. Revista de Administração Pública. Rio de Janeiro, vol.54, n, 4, p.1134-1145, julho/agosto, 2020.

ALPINO, Taís de Moura Araújo; SANTOS, Claúdia Roberta Bocca; BARROS, Denise Cavalcanti de; FREITAS, Carlos Machado de. COVID-19 e (in)segurança alimentar e nutricional: ações do Governo Federal brasileiro na pandemia frente aos desmontes orçamentários e institucionais. Cadernos de Saúde Pública, Rio de Janeiro, v.36, n. 8, 2020.

BEZERRA, Isabelle Germano Coelho; TABAI, Katia Cilene. Segurança Alimentar: A intersetorialidade em municípios do estado do Rio de Janeiro, Brasil. Revista Sodebras, vol. 13, n.145, p.60-66. 2018, janeiro, 2018.

BRASIL. Casa Civil. Lei n ${ }^{\circ} 11.346$, de 15 de setembro de 2006. Cria o Sistema Nacional de Segurança Alimentar e Nutricional - SISAN com vistas em assegurar o direito humano a alimentação adequada e dá outras providências. Brasília, DF, 2006. Disponível em: http://www.planalto.gov.br/ccivil_03/_ato2004-2006/2006/Lei/L11346.htm>. Acesso em 01 de setembro de 2017.

BRASIL. Constituição da República Federativa do Brasil. 1988. Disponível em: <https://www2.senado.leg.br/bdsf/bitstream/handle/id/518231/CF88_Livro_EC91_2016.pdf>.

Acesso em: 21 de agosto de 2019.

CAPORAL, Francisco Roberto; COSTABEBER, José Antonio. Agroecologia: alguns conceitos e princípios. 1ed. Brasília: MDA/SAF, 2004.

CUSTÓDIO, André Viana; SILVA, Cicero Ricardo Cavalcante da. A Intersetorialidade nas Políticas Sociais e Públicas. In: Seminário Nacional: demandas sociais e políticas públicas, 10., 2015. Santa Cruz do Sul. Anais eletrônicos. Santa Cruz do Sul: Imprensa Livre, 2015. P.106-125. Disponível em: <http://online.unisc.br/acadnet/anais/index.php/snpp/issue/view/64>. Acesso em 24 fevereiro de 2019.

EMATERCE. Empresa de Assistência Técnica e Extensão Rural do Ceará. Ematerce e SDA introduzem plantio protegido para produção de hortaliças. Juazeiro do Norte, 2020. Disponível em:< https://www.ematerce.ce.gov.br/2019/12/17/juazeiro-do-norte-ematerceintroduz-plantio-protegido-para-producao-de-hortalicas/>. Acesso em 10 de fevereiro de 2021.

FAO. Organização das Nações Unidas para Alimentação e Agricultura. Cadernos de atividades: trabalhando pela fome zero. 2018. Brasília, 2018. Disponível em: <http://www.fao.org/3/i9420pt/I9420PT.pdf>. Acesso em 14 de dezembro de 2020. 
FNDE. Fundo Nacional de Desenvolvimento da Educação. Dados da Agricultura familiar. 2018. Disponível em: < http://www.fnde.gov.br/programas/alimentacaoescolar/alimentacaoescolarconsultas/dados-da-agriculturafamiliar>. Acesso em 10 de fevereiro de 2021.

IBGE. Instituto Brasileiro de Geografia e Estatística. Pesquisa Nacional por Amostra de Domicílios Contínua (PNAD) COVID-19. 2020. Disponível em: <ftp://ftp.ibge.gov.br/Trabalho_e_Rendimento/Pesquisa_Nacional_por_Amostra_de_ Domicilios_PNAD_COVID19/Microdados/PNAD_ COVID19_052020.zip>. Acesso em $12 / 12 / 2020$.

Censo Agropecuário 2017 - Dados Preliminares. Rio de Janeiro, 2018. Disponível em: https://censos.ibge.gov.br/agro/2017/ Acesso em 17/12/2018.

IPECE. Instituto de Pesquisa Econômica do Ceará. Instituto de pesquisa e estratégia econômica do Ceará. Anuário 2010. Disponível em: http://www.ipece.ce.gov.br. Acesso em: 29/05/2017.

LAKATOS, Eva Maria; MARCONI, Marina de Andrade. Fundamentos de metodologia científica. São Paulo: Atlas, 2001.

MALUF, R. S. Tempos sombrios de pandemia e fome: responsabilidades da pesquisa em soberania e segurança alimentar e nutricional. Segurança Alimentar e Nutricional. Campinas, vol. 27, p. 1-5, junho, 2020. Disponível em: https://periodicos.sbu.unicamp.br/ojs/index.php/san/article/view/8659467/22341 Acesso em 10/02/2021.

MAGALHÃES, Rosa. Avaliação de políticas e iniciativas públicas de Segurança Alimentar e Nutricional: dilemas e perspectivas metodológicas. Ciência \& Saúde Coletiva: Rio de Janeiro, vol.19, n.5, p.1339-1346, maio, 2014.

MEIRELLES, Laércio. Soberania Alimentar, agroecologia e mercados locais. Agriculturas: Rio de Janeiro, vol.1, p.11-14, setembro, 2004.

MONTEIRO, Barbara Leandro; TABAI, Katia Cilene; BEZERRA, Isabelle Germano Coelho; PINTO, Mariára Aparecida Miranda; DIAS, Anelise. Reflexões sobre políticas de fortalecimento da agricultura familiar e segurança alimentar e nutricional no município de Seropédica -RJ. In: SANTOS, Cleberton Correia. (Org.). Agroecologia: debates sobre a sustentabilidade. Ponta Grossa: Editora Atena, 2019, p. 1-13.

MONTEIRO, Barbara Leandro; DIAS, Anelise; TABAI, Katia Cilene. Políticas Intersetoriais de Segurança Alimentar e Nutricional no Município de Seropédica, Rio de Janeiro-Brasil. Cadernos de Agroecologia. Campo Grande, v.13, p.1 - 10, 2018.

Políticas Públicas de Fortalecimento da Agricultura Familiar e Segurança Alimentar e Nutricional. In: SARTÓRIO, Lúcia Aparecida Valadares et al. (Org.). Políticas Públicas e Práticas Sociais: Cidadania, saúde, Educação, comunicação e Segurança Alimentar. São Paulo: Editora Livraria da Física. 2020, p.213-225.

NEVES, Daniele Custódio Gonçalves; TABAI, Katia Cilene. Analysis of the National School Food Program (NSFP) like Public Policy on Food and Nutrition Security in Brazil. In: International Conference on Childhood Obesity - Conference Book. Lisboa, Portugal, 2017, p.8485 . 
NEVES, Daniele Custódio Gonçalves. Análise de Políticas Públicas Intersetoriais de Fortalecimento da Agricultura Familiar e de Segurança Alimentar e Nutricional no Brasil e o caso de um município do Espírito Santo. Rio de Janeiro: IF/UFRRJ, 2018. 104f. Dissertação (Mestrado em Práticas em Desenvolvimento Sustentável).

NEVES, Daniele Custódio Gonçalves; TABAI, Katia Cilene. Políticas Públicas Intersetoriais de Segurança Alimentar e Nutricional no Brasil. In: SARTÓRIO, Lúcia AparecidaValadares et al. (Org.). Políticas Públicas e Práticas Sociais: Cidadania, saúde, Educação, comunicação e Segurança Alimentar. São Paulo: Editora Livraria da Física, 2020, p. 49 - 68.

SAMBUICHI, Regina Helena Rosa; ALMEIDA, Ana Flavia Cordeiro Souza de; PERIN, Gabriela; SPÍNOLA, Paulo Asafe Campos; PELLA, Antonio Fernando Costa. O Programa de Aquisição de Alimentos (PAA) como estratégia de enfrentamento aos desafios da COVID-19. Revista de Administração Pública: Rio de Janeiro, v.54, n. 4, P. 1079-1096, julho/agosto, 2020.

SANTOS, Letícia Ribeiro Pinto. Residência agronômica com enfoque agroecológico: o caso dos canais de venda direta na UFRRJ. Seropédica (RJ): UFRRJ, 2018.146f. Dissertação (Mestrado Profissional em Agricultura Orgânica).

SDA. Secretaria do Desenvolvimento Agrário. Cooperativas de Juazeiro do Norte e Altaneira recebem cestas e kits de higiene. Juazeiro do Norte, 2020 Disponível em: <https://www.sda.ce.gov.br/2020/07/10cooperativas-de-juazeiro-do-norte-e-altaneira-recebemcestas-de-alimentos-e-kits-de-higiene/>. Acesso em 10/02/2021.

SILVA, José Graziano. Agora, defender-se do vírus... E depois? Segurança Alimentar e Nutricional: Campinas, vol. 27, p. 1-4, junho, 2020. Disponível em: https://periodicos.sbu.unicamp.br/ojs/index.php/san/article/view/8659467/22341 Acesso em 10/02/2021.

SUS. Sistema Único de Saúde. Painel Coronavírus. Brasília, 2021. Disponível em:<https://covid.saude.gov.br/>. Acesso em 04/02/2021.

TABAI, Katia Cilene. Segurança alimentar e Nutricional no contexto da intersetorialidade. In: AZEREDO, Denise Rosane Perdomo. (Org.). Inocuidade dos alimentos. Vol. 1, 1 Ed. Rio de Janeiro: Atheneu, 2017, p. 19-30.

VALADARES, Alexandre Arbex; ALVES, Fábio; GALIZA, Marcelo; SILVA, Sandro Pereira. Agricultura familiar e abastecimento alimentar no contexto do Covid-19: uma abordagem das ações públicas emergenciais. Nota Técnica no 69. Brasília, DF: Ipea. 2020. 